\title{
KNOWLEDGE AND HEALTH SEEKING BEHAVIOR RELATED TO KALA-AZAR IN RURAL COMMUNITIES OF EAST CHAMPARAN DISTRICT, BIHAR
}

\begin{abstract}
NAVIN KUMAR ${ }^{1 *}$, SINGH TB ${ }^{2}$, MEENA LP ${ }^{3}$
${ }^{1}$ Department of Community Medicine, Institute of Medical Sciences, Banaras Hindu University, Varanasi - 221 005, Uttar Pradesh, India. ${ }^{2}$ Department of Community Medicine, Division of Biostatistics, Institute of Medical Sciences, Banaras Hindu University, Varanasi - 221005 , Uttar Pradesh, India. ${ }^{3}$ Department of Medicine, Institute of Medical Sciences, Banaras Hindu University, Varanasi - 221 005, Uttar Pradesh, India. Email: navin.bhu2016@gmail.com
\end{abstract}

Received: 12 April 2017, Revised and Accepted: 19 May 2017

\section{ABSTRACT}

Objective: To find out the sociodemographic characteristics, knowledge and health seeking behavior related to KA in the East Champaran district, Bihar among study subject.

Methods: A case-control study was conducted to understand the knowledge and health seeking behavior related to KA in the East Champaran district. A total of 100 KA cases and 100 healthy controls selected from the neighborhoods of cases.

Results: The knowledge of the population showed that the male constituted $58 \%$ of the total population in which $56 \%$ were case and $60 \%$ were control. Majority of the respondent $76.5 \%$ were aware from the KA. Maximum of the respondent $72.5 \%$ believed that biting time of sand flies were in the night. Moreover, $71 \%$ respondent cannot know how to protect the KA transmission.

Conclusion: These results will be useful for further improvement in the KA control programs for intervention strategies. The knowledge of the study subject about KA, the vectors, the transmission of KA, and control measures was poor which needs some effort of the public health system by the Ministry working in the field of health.

Keywords: Kala-azar, East Champaran, Case-control, Sand flies.

(C) 2017 The Authors. Published by Innovare Academic Sciences Pvt Ltd. This is an open access article under the CC BY license (http://creativecommons. org/licenses/by/4. 0/) DOI: http://dx.doi.org/10.22159/ajpcr.2017.v10i9.19110

\section{INTRODUCTION}

Kala-azar (KA) is a chronic and potentially fatal parasitic disease of the internal organs, which affect the organs due to infection by Leishmania donovani. Leishmania parasites are dimorphic, alternating between promastigote and amastigote form during their life-cycle [1]. Parasitic diseases are distributed the worldwide, with a higher prevalence in developing countries, especially in areas with inadequate sanitation [2]. The worldwide burden of this disease is estimated to be between 146,700 and 282,800 cases per year [3].

It is a major cause of morbidity and mortality and of tremendous public health priority in India, Bangladesh, and Nepal. KA excessively impinges on the poor, mostly individuals with defenseless homes as well as ecological settings. Low daily earnings together with poor health systems aggravate the productivity of underprivileged communities. An elimination campaign has been running in the India, Nepal, Bangladesh, Bhutan, and Thailand since 2005. Three elimination time frames currently exist; the first, ending in 2015, was to establish progress that has been made; the second is the elimination of KA as a public health problem by 2017 (committed to by Indian subcontinent governments and KA programme managers); the third, as part of the London Declaration on neglected tropical diseases, is to eliminate KA as a public health problem by 2020 (defined as $<1$ case of KA in 10,000 people in endemic areas, at the block [India] and Upazila [subdistrict; Bangladesh] level in the Indian subcontinent) [4].

An estimated 200 million people are in at risk, India, Nepal, and Bangladesh harbor and these contribute an estimated $67 \%$ of the global KA disease burden [5]. 50\% of KA cases worldwide occur in India. In India, it is endemic in the states of Bihar, West Bengal, Uttar Pradesh, and Jharkhand, but only Bihar state contributes more than $90 \%$ of the cases of KA [6]. India is under KA elimination mode; therefore a reduction in KA incidence has been the key developmental goal for monitoring the progress of the National Elimination Program. The need of setting such goals has been discussed and documented in various national and international deliberations and brainstorming meetings at office of the directorate, National Vector Borne Disease Control Programme, New Delhi $[7,8]$. KA is familiar to communities in Bihar. Maximum research activities concerning KA have primarily focused on the characteristics of the parasite and the host. Therefore, a case-control study was conducted to determine sociodemographic, knowledge and health seeking behavior of respondent.

An indirect indication of the dearth of published research about perceptions concerning KA in the old world is the total absence of references to any socio-behavioral research publications about KA in the above-mentioned studies. Such knowledge may guide future health education efforts contributing to KA control in East Champaran district, Bihar. The aim of this study, therefore, was to gain a better understanding of the knowledge and health seeking behavior of KA sufferers and their carriers regarding the disease in East Champaran district, Bihar. Higher rates of morbidity and mortality, especially related to infectious diseases, were wellrecognized concomitants of poverty. KA has strong links with poverty and is generally ranked as one of the "most neglected" diseases [9]. Of the classic neglected diseases, it has the greatest impact, both in the magnitude of its morbidity and mortality, and its wide geographical distribution [10]. 
Poverty is associated with ecological factors that increase risk, such as poor housing conditions (cracked mud walls that provide daytime resting places for sand flies, damp earthen floors that prolong sand fly survival, open areas in the walls that enable sand fly entry) and sleeping outside or on the ground [11-15]. Poverty can also increase disease progression, morbidity and mortality, most pervasively through poor nutrition. A large proportion of children and women in Asia and Africa have poor protein-energy, iron, vitamin A and zinc nutritional status as a result of inadequate intake and, among women, childbearing and lactation. A poorly nourished person with leishmanial infection is more likely to progress to $\mathrm{KA}[16,17]$.

The study area was East Champaran District of Bihar. Presently East Champaran consists of 6 sub-division and 27 blocks. The district covers an area of 3968.0 sq. km. The main rivers of the East Champaran are Gandak, Budhi Gandak and Bagmati. The district lies on the northern end of the state Bihar. It touches the Indo-Nepal border. There are 6 subdivision and 27 community development block in the district. There are 1293 village, 405 Panchayat and 10 statutory towns in the district (2011 census).

East Champaran is an important pilgrim center for both Buddhists and Hindus. They are Shiv Mandir at Areraj, Kesariya Bodh Stupa and Gandhi memorial. It is $153 \mathrm{~km}$ from Patna and just after crossing river Ganga. East Champaran latitude $=26.6098^{\prime} \mathrm{N}$ and longitude $=84.8568$ ' E. The total population of district was $50,82,868$ with $2,681,209$ males and $2,418,162$ females, literacy rate as 58.26 and sex ratio of $901 / 1000$ as per 2011 census.

\section{Objective}

To find out the sociodemographic characteristics of the study subjects.

To assess the knowledge and health seeking behavior related to KA in the East Champaran district, Bihar among study subject.

\section{METHODS}

\section{Study design}

A case-control study was adopted in this study.

\section{Study duration}

The data have been collected during the period June 2016 to November 2016 from East Champaran District of Bihar.

\section{Study subjects}

The KA registered cases at a government hospital in the year 2014 of East Champaran District.

\section{Selection of controls}

Controls were selected from neighborhood of the cases other than KA.

\section{Inclusion criteria}

All the KA cases aged 2 years and above were included in the study.

\section{Exclusion criteria}

Cases $<2$ year were excluded from the study.

\section{Study area}

The data for this study were collected from the East Champaran district of Bihar. All 100 confirmed KA cases were taken from the blocks of East Champaran district and 100 controls were taken from the neighborhood of the cases. The KA cases were taken in the study from January 2014 to December 2014. Informed consent was obtained from all cases and controls subjects before including them in the study.

\section{Sample size}

In this study, $100 \mathrm{KA}$ cases were taken from the study area and 100 healthy controls from neighborhood of the cases. There are 27 blocks in the East Champaran district. Out of which, 12 blocks had reported KA cases more than 20, in the year 2014. Five blocks having a larger number of KA cases were chosen randomly. From each block, $20 \mathrm{KA}$ cases were taken as per convenience.

\section{Data collection}

A schedules method was used for collection of data. It includes a sociodemographic profile of study group, level of knowledge and health seeking behavior of KA as the study subjects from the East Champaran district of Bihar

\section{Statistical technique}

The data were initially entered into Microsoft Excel and then transferred to trail version of SPSS 16.0. The number and percentage of gender, age group, marital status, education, total number of family member, income, and occupation for case and control group were determined. Furthermore, knowledge of the respondent about KA, knowledge of the respondent about the vector of KA and health seeking behavior of the study population in the East Champaran District, Bihar were calculated.

\section{RESULTS}

Sociodemographic characteristics of the study subjects

In this study, Table 1 showed that the male constituted $58 \%$ of the total population, in which $56 \%$ were case and $60 \%$ were control. Female constituted $42 \%$ of the total population in which $44 \%$ were case and $40 \%$ were control of the total study population. Residents $<15$ years of age were $36.5 \%, 15-30$ years of age group were $21 \%, 31-45$ years of age group were $20 \%, 46-60$ years of age group were $18 \%$, and only $4.5 \%$ of the population were $>60$ years of age. More study population $53 \%$ were married and only $46 \%$ were unmarried. Maximum people in the study population were illiterate $52.5 \%$ and only $47.5 \%$ people were literate. The majorities of the study population were farmer and in private job but some $10 \%$ were unemployed.

\section{Knowledge of the respondent about KA}

The results showed that majority of the respondent $76.5 \%$ were aware from the KA (Table 2). The fact that KA is an infectious disease and can be transmitted from one person to another person was answering yes $24 \%$ of the study population. Furthermore, only $18 \%$ of the study subjects know that KA was transmitted from the sand flies.

Table 1: Sociodemographic characteristics of the study subjects in the East Champaran district, Bihar

\begin{tabular}{|c|c|c|c|}
\hline \multirow{2}{*}{$\begin{array}{l}\text { Sociodemographic } \\
\text { characteristics }\end{array}$} & \multicolumn{3}{|c|}{ Study group (\%) } \\
\hline & Case & Control & Total \\
\hline \multicolumn{4}{|l|}{ Gender } \\
\hline Male & $56(56)$ & $60(60)$ & $116(58)$ \\
\hline Female & $44(44)$ & $40(40)$ & $84(42)$ \\
\hline \multicolumn{4}{|l|}{ Age group (in years) } \\
\hline$<15$ & $42(42)$ & $31(31)$ & $73(36.5)$ \\
\hline $15-30$ & $23(23)$ & $19(19)$ & $42(21)$ \\
\hline $31-45$ & $23(23)$ & $17(17)$ & $40(20)$ \\
\hline $46-60$ & $8(8)$ & $28(28)$ & $36(18)$ \\
\hline$>60$ & $4(4)$ & 50 & $9(4.5)$ \\
\hline \multicolumn{4}{|l|}{ Marital status } \\
\hline Married & $45(45)$ & $61(61)$ & $106(53)$ \\
\hline Unmarried & $54(54)$ & $38(38)$ & $92(46)$ \\
\hline Widow & $1(1)$ & $1(1)$ & $2(1)$ \\
\hline \multicolumn{4}{|l|}{ Educational status } \\
\hline Illiterate & $46(46)$ & $59(59)$ & $105(52.5)$ \\
\hline Literate & $54(54)$ & $41(41)$ & $95(47.5)$ \\
\hline \multicolumn{4}{|c|}{ Number of family members } \\
\hline$<5$ & $8(8)$ & $9(9)$ & $17(8.5)$ \\
\hline $5-8$ & $51(51)$ & $62(62)$ & $113(56.5)$ \\
\hline$>8$ & $41(41)$ & $29(29)$ & $70(35)$ \\
\hline \multicolumn{4}{|c|}{ Occupation of head of household } \\
\hline Unemployed & $10(10)$ & $10(10)$ & $20(10)$ \\
\hline Private job & $28(28)$ & $25(25)$ & $53(26.5)$ \\
\hline Farmer & $45(45)$ & $45(45)$ & $90(45)$ \\
\hline Others & $17(17)$ & $20(20)$ & 37 (18.5) \\
\hline
\end{tabular}


Table 2: Knowledge of the respondent about KA in the East Champaran District, Bihar

\begin{tabular}{|c|c|c|c|c|}
\hline \multirow[t]{2}{*}{ Knowledge } & \multirow[t]{2}{*}{ Responses } & \multicolumn{3}{|c|}{ Study group (\%) } \\
\hline & & Case & Control & Total \\
\hline Know about KA & Yes & $82(82)$ & $71(71)$ & $153(76.5)$ \\
\hline \multirow[t]{3}{*}{ KA can be transmitted from person to person } & Yes & $34(34)$ & $14(14)$ & $48(24)$ \\
\hline & No & $24(24)$ & $23(23)$ & $47(23.5)$ \\
\hline & I don't know & $42(42)$ & $63(63)$ & $105(52.5)$ \\
\hline \multirow[t]{3}{*}{ Complete cure of $\mathrm{KA}$ is possible } & Yes & $75(75)$ & $42(42)$ & $117(53)$ \\
\hline & No & $8(8)$ & $11(11)$ & $19(9.5)$ \\
\hline & I don't know & $17(17)$ & $47(47)$ & $64(32)$ \\
\hline \multirow[t]{3}{*}{ How is KA transmitted } & Sand flies & $22(22)$ & $14(14)$ & $36(18)$ \\
\hline & Other insect & 55 (55) & $44(44)$ & $99(49.5)$ \\
\hline & I don't know & $23(23)$ & $42(42)$ & $65(32.5)$ \\
\hline
\end{tabular}

KA: Kala-azar

Table 3: Knowledge of the respondent about vector of KA in the East Champaran district, Bihar

\begin{tabular}{|c|c|c|c|c|}
\hline \multirow[t]{2}{*}{ Item } & \multirow[t]{2}{*}{ Response } & \multicolumn{3}{|c|}{ Study group (\%) } \\
\hline & & Cases & Control & Total \\
\hline \multirow[t]{2}{*}{ Which hospital you go when sick } & Government & $68(68)$ & $61(61)$ & $129(64.5)$ \\
\hline & Private & $32(32)$ & $39(39)$ & $71(35.5)$ \\
\hline \multirow{3}{*}{ Use bed net during night } & Always & 17 (17) & $17(17)$ & 34 (17) \\
\hline & Sometimes & 35 (35) & 75 (75) & $110(55)$ \\
\hline & Never & $48(48)$ & $8(8)$ & $56(28)$ \\
\hline \multirow{2}{*}{ Did DDT was sprayed in the house } & Yes & 85 (85) & $77(61)$ & $162(81)$ \\
\hline & No & $15(15)$ & $23(23)$ & 38 (19) \\
\hline \multirow[t]{2}{*}{ Can you protect from the KA transmission } & Yes & $34(34)$ & $24(24)$ & $58(29)$ \\
\hline & No & $66(66)$ & $76(76)$ & 142 (71) \\
\hline
\end{tabular}

KA: Kala-azar, DDT: Dichlorodiphenyltrichloroethane

Table 4: Health seeking behavior of the study population in the East Champaran district, Bihar

\begin{tabular}{|c|c|c|c|c|}
\hline \multirow[t]{2}{*}{ Knowledge } & \multirow[t]{2}{*}{ Responses } & \multicolumn{3}{|c|}{ Study group (\%) } \\
\hline & & Case & Control & Total \\
\hline \multirow[t]{4}{*}{ Sand flies breeds in } & House & $39(39)$ & $29(29)$ & $68(34)$ \\
\hline & Hospital & $5(3)$ & $3(3)$ & $8(4)$ \\
\hline & Field area around village & $26(26)$ & $27(27)$ & $53(26.5)$ \\
\hline & I don't know & $30(30)$ & $41(41)$ & $71(35.5)$ \\
\hline \multirow[t]{3}{*}{ Biting time of the sand flies } & Evening & $13(13)$ & $15(15)$ & $28(14)$ \\
\hline & During night & $75(75)$ & $70(70)$ & $145(72.5)$ \\
\hline & At any time & $12(12)$ & $15(15)$ & $27(13.5)$ \\
\hline
\end{tabular}

\section{Knowledge of the respondent about vector of KA}

Table 3 shows data on the knowledge of the respondent about the vector of KA in East Champaran district. 34\% of the respondent believed that sand flies breeds in the house, $26.5 \%$ believed that sand flies breeds' field area around villages also $35.5 \%$ of the respondent had no any idea about breeding of sand flies. Majority of the respondent 72.5 believed that biting time of sand flies were in the night.

Health seeking behavior of the study subject

In Table 4, more than half of the respondent (64.5\%) preferred government hospital and only (35.5\%) visit private hospital when they were sick. Maximum of the respondent (55\%) use bed net during the night sometimes and very few of them (17\%) use bed net always in the night during sleeping. The result showed that $81 \%$ of the respondent said that dichlorodiphenyltrichloroethane was spared in the house. However, maximum of the respondent (71\%) cannot know how to protect the KA transmission.

\section{DISCUSSION}

In this study, cases and controls were interviewed to know their understanding the level of the knowledge of the respondent of the community toward KA can be the key to success of the planning an elimination program in East Champaran district, Bihar. In this study, we know the knowledge of the respondent about vector of KA and KA related attitude and practices in the East Champaran district, Bihar.

The main result of the study related characteristics of cases and controls was obtained on their age, gender, education status, marital status, and occupation of the head of the household and total family members in the house. Most of the respondents of East Champaran were males $(58 \%)$ and the females were (42\%). Majority of the respondent were below age 15 years followed by 15-30 years age group were (21\%), $31-45$ years age group were (20\%), and only (4.5\%) respondent were more than 60 years. Maximum of the respondent was married (53\%) and illiterate $(52.5 \%)$. The low level of education in the East Champaran District might render the control strategies of the disease in the area endemic with KA. Most of the people in the East Champaran were farmers (45\%) followed by private job (26.5\%) and unemployed (10\%). The occupation might represent risk factors for KA infection because it has been thought that the transmission of the disease takes place also through vegetation. The presence of vegetation as a risk factor of KA has also been previously reported [18]. 
Most of the respondent (76.5\%) had known about KA. This result similar to that was reported in Mondal et al. [4]. More than $50 \%$ of the respondents don't know the transmission of KA also through person to person, but $58.5 \%$ of the respondent had knowledge that complete cure of KA. However, very less knowledge about transmission of KA through sand flies (18\%). Furthermore, more or less the knowledge about breeding site of sand flies was poor where only $(34 \%)$ of the respondent believed that the sand flies breeds in the houses. Mud walls can retain moisture for many months after the rainy season, which further increases favorable conditions for sand fly breeding and resting [19].

The knowledge of breeding places is very important in the view of the decision-making capacity and participation of the community in a successful control campaigns again KA. Maximum of the respondent $(72.5 \%)$ respond that biting time of sand flies were during the night. Since majority of the study subject were illiterate so had no idea how they protect from the KA transmission. Only (29\%) respondent gave his/her idea. Most of the patients (64.5\%) want to go government hospital when they were sick.

\section{CONCLUSION}

The findings drawn from this study suggest that these study results emphasize the need for increasing KA awareness activities through involving the health workers and the school in the community on a massive scale. The knowledge of the study subject about KA, the vectors, the transmission of KA and control measures was poor which needs some effort of the public health system by the Ministry of Health and other agencies working in the field of health. Although there is a long history of this disease in the East Champaran, the lack of knowledge and health seeking behavior toward KA will remain a serious problem for the health policy planners to get efficient support from the community to control KA in the East Champaran, Bihar.

\section{ACKNOWLEDGMENT}

Authors are extremely thankful to Primary Health Centre, East Champaran, Bihar, for data collection. Authors also want to thank local Gram Pradhans for helping and introducing them to localities. Authors want to acknowledge Banaras Hindu University for providing financial assistance.

\section{REFERENCES}

1. Ghosh P, Mondal S, Bera T. Preparation and characterization of andrographolide nanoparticles for visceral leishmaniasis chemotherapy:
In vitro and in vivo evaluations. Int J Pharm Pharm Sci 2016;8(12):102-7.

2. Issa R. Tropical parsiticlung diseases. Int $J$ Pharm Pharm Sci 2015;7(5):2-12.

3. Alvar J, Vélez ID, Bern C, Herrero M, Desjeux P, Cano J, et al. Leishmaniasis worldwide and global estimates of its incidence. PLoS One 2012;7(5):e35671.

4. Mondal D, Singh SP, Kumar N, Joshi A, Sundar S, Das P, et al. Visceral leishmaniasis elimination programme in India, Bangladesh, and Nepal: Reshaping the case finding/case management strategy. PLoS Negl Trop Dis 2009;3:e355.

5. Stauch A, Sarkar RR, Picado A, Ostyn B, Sundar S, Rijal S, et al. Visceral leishmaniasis in the Indian subcontinent: Modelling epidemiology and control. PLoS Negl Trop Dis 2011;5(11):e1405.

6. Perry D, Dixon K, Garlapati R, Gendernalik A, Poché D, Poché R. Visceral leishmaniasis prevalence and associated risk factors in the saran district of Bihar, India, from 2009 to July of 2011. Am J Trop Med Hyg 2013;88(4):778-84.

7. A Consultation Meeting on Indicators for Kala-Azar Elimination Organized at SEARO Office. New-Delhi in June, 09.

8. Brain Storming Session Meeting at National Vector Borne Diseases Control Programme Office, New-Delhi on $19^{\text {th }}$ January; 2011.

9. Yamey G, Torreele E. The world's most neglected diseases. Br Med J 2002;325:176-7.

10. Hotez PJ, Hotez PJ, Remme JH, Buss P, Alleyne G, Morel C, et al. Combating tropical infectious diseases: Report of the disease control priorities in developing countries project. Clin Infect Dis 2004;38:871-8.

11. Ranjan A, Sur D, Singh VP, Siddique NA, Manna B, Lal CS, et al. Risk factors for Indian kala-azar. Am J Trop Med Hyg 2005;73(1):74-8.

12. Bern C, Hightower AW, Chowdhury R, Ali M, Amann J, Wagatsuma Y, et al. Risk factors for kala-azar in Bangladesh. Emerg Infect Dis 2005;11:655-62.

13. Barnett PG, Singh SP, Bern C, Hightower AW, Sundar S. Virgin soil: The spread of visceral leishmaniasis into Uttar Pradesh, India. Am J Trop Med Hyg 2005;73(4):720-5.

14. Bern C, Joshi AB, Jha SN, Das ML, Hightower A, Thakur GD, et al. Factors associated with visceral leishmaniasis in Nepal: Bed-net use is strongly protective. Am J Trop Med Hyg 2000;63(3-4):184-8.

15. Quinnell RJ, Dye C. Correlates of the peridomestic abundance of Lutzomyia longipalpis (Diptera: Psychodidae) in Amazonian Brazil. Med Vet Entomol 1994;8(3):219-24

16. Cerf BJ, Jones TC, Badaro R, Sampaio D, Teixeira R, Johnson WD Jr. Malnutrition as a risk factor for severe visceral leishmaniasis. J Infect Dis 1987;156(6):1030-3.

17. Harrison LH, Naidu TG, Drew JS, de Alencar JE, Pearson RD. Reciprocal relationships between undernutrition and the parasitic disease visceral leishmaniasis. Rev Infect Dis 1986;8(3):447-53.

18. Dhiman RC, Sen AB. Epidemiology of kala-azar in rural Bihar (India) using village as a component unit of study. Indian J Med Res 1991;93:155-60.

19. Napier LE. An epidemiological consideration of the transmission of Kala-azar in India. India Med Res Mem 1926;4:219-65. 